\title{
Adaptations to different habitats in sexual and asexual populations of parasitoid wasps: a meta- analysis (\#17587)
}

First revision

Please read the Important notes below, the Review guidance on page 2 and our Standout reviewing tips on page 3 . When ready submit online. The manuscript starts on page 4.

Important notes

\section{Editor}

Donald Kramer

Files

1 Tracked changes manuscript(s)

1 Rebuttal letter(s)

2 Figure file(s)

1 Table file(s)

Please visit the overview page to download and review the files not included in this review PDF.

Declarations

This article is a Systematic review or Meta Analysis. 
Please read in full before you begin

\section{How to review}

When ready submit your review online. The review form is divided into 5 sections. Please consider these when composing your review:

\section{BASIC REPORTING}

2. EXPERIMENTAL DESIGN

3. VALIDITY OF THE FINDINGS

4. General comments

5. Confidential notes to the editor

You can also annotate this PDF and upload it as part of your review

To finish, enter your editorial recommendation (accept, revise or reject) and submit.

\section{BASIC REPORTING}

Clear, unambiguous, professional English language used throughout.

Intro \& background to show context. Literature well referenced $\&$ relevant.

Structure conforms to PeerJ standards, discipline norm, or improved for clarity.

Figures are relevant, high quality, well labelled \& described.

Raw data supplied (see PeerJ policy).

\section{EXPERIMENTAL DESIGN}

Original primary research within Scope of the journal.

Research question well defined, relevant $\&$ meaningful. It is stated how the research fills an identified knowledge gap.

Rigorous investigation performed to a high technical \& ethical standard.

Methods described with sufficient detail \& information to replicate.

\section{VALIDITY OF THE FINDINGS}

Impact and novelty not assessed. Negative/inconclusive results accepted. Meaningful replication encouraged where rationale $\&$ benefit to literature is clearly stated.

Data is robust, statistically sound, $\&$ controlled.
Conclusions are well stated, linked to original research question \& limited to supporting results.

Speculation is welcome, but should be identified as such.

The above is the editorial criteria summary. To view in full visit https://peerj.com/about/editorialcriteria/ 
The best reviewers use these techniques

Tip

\author{
Support criticisms with \\ evidence from the text or from \\ other sources
}

\section{Give specific suggestions on how to improve the manuscript}

\section{Comment on language and grammar issues}

Organize by importance of the issues, and number your points

\section{Example}

Smith et al (J of Methodology, 2005, V3, pp 123) have shown that the analysis you use in Lines 241-250 is not the most appropriate for this situation. Please explain why you used this method.

Your introduction needs more detail. I suggest that you improve the description at lines 57- 86 to provide more justification for your study (specifically, you should expand upon the knowledge gap being filled).

The English language should be improved to ensure that your international audience can clearly understand your text. I suggest that you have a native English speaking colleague review your manuscript. Some examples where the language could be improved include lines 23, 77, 121, 128 - the current phrasing makes comprehension difficult.

1. Your most important issue

2. The next most important item

3. ...

4. The least important points

Line 56: Note that experimental data on sprawling animals needs to be updated. Line 66: Please consider exchanging "modern" with "cursorial".

I thank you for providing the raw data, however your supplemental files need more descriptive metadata identifiers to be useful to future readers. Although your results are compelling, the data analysis should be improved in the following ways: $A A, B B, C C$

I commend the authors for their extensive data set, compiled over many years of detailed fieldwork. In addition, the manuscript is clearly written in professional, unambiguous language. If there is a weakness, it is in the statistical analysis (as I have noted above) which should be improved upon before Acceptance.
Comment on strengths (as well as weaknesses) of the manuscript




\title{
Adaptations to different habitats in sexual and asexual populations of parasitoid wasps: a meta-analysis
}

\author{
Isabelle Amat $^{\text {Corresp., }}{ }^{1}$, Jacques JM van Alphen ${ }^{2}$, Alex Kacelnik ${ }^{3}$, Emmanuel Desouhant ${ }^{1}$, Carlos Bernstein ${ }^{\text {Corresp }}$ \\ ${ }^{1}$ UMR CNRS 5558 Biometrie et Biologie Evolutive, Univ Lyon; Université Claude Bernard (Lyon I), Villeurbanne, France \\ 2 IBED, University of Amsterdam, Amsterdam, Netherlands \\ 3 Department of Zoology, University of Oxford, Oxford, UK, United Kingdom \\ Corresponding Authors: Isabelle Amat, Carlos Bernstein \\ Email address: isabelle.amat@univ-lyon1.fr, carlos.bernstein@gmail.com
}

Background. Coexistence of sexual and asexual populations remains a key question in evolutionary ecology. We address the question how an asexual and a sexual form of the parasitoid Venturia canescens can coexist in southern Europe. We test the hypothesis that both forms are adapted to different habitats within their area of distribution. Sexuals inhabit natural environments that are highly unpredictable, and where density of wasps and their hosts is low and patchily distributed. Asexuals instead are common in anthropic environments (e.g. grain stores) where host outbreaks offer periods when egg-load is the main constraint on reproductive output.

Methods. We present a meta-analysis of known adaptations to these habitats. Differences in behavior, physiology and life-history traits between sexual and asexual wasps were standardized in term of effect size (Cohen's $d$ value, Cohen, 1988).

Results. Seeking consilience from the differences between multiple traits, we found that sexuals invest more in longevity at the expense of egg-load, are more mobile, and display higher plasticity in response to thermal variability than asexual counterparts.

Discussion. Thus, each form has consistent multiple adaptations to the ecological circumstances in the contrasting environments. 


\section{Adaptations to different habitats in sexual and asexual populations of}

\section{parasitoid wasps: a meta-analysis}

4 Running header: Adaptations in sexual and asexual wasps

6 Amat* I, van Alphen JJM**, Kacelnik A***, Desouhant* E, Bernstein* C

8 * Univ Lyon, Université Claude Bernard Lyon 1, CNRS, UMR 5558, Laboratoire de Biométrie et

9 Biologie Evolutive, F-69100, Villeurbanne, France.

$10 * *$ University of Amsterdam, IBED, P.O. Box 942481090 GE Amsterdam, Netherlands.

$11 * * *$ Department of Zoology, Oxford University, Oxford OX1 3PS, UK.

13 Corresponding authors: Carlos Bernstein (carlos.bernstein@gmail.com), Isabelle Amat

14 (isabelle.amat@univ-lyon1.fr)

18 Abstract:

19 Background. Coexistence of sexual and asexual populations remains a key question in

20 evolutionary ecology. We address the question how an asexual and a sexual form of the parasitoid

21 Venturia canescens can coexist in southern Europe. We test the hypothesis that both forms are 
22 adapted to different habitats within their area of distribution. Sexuals inhabit natural environments

23 that are highly unpredictable, and where density of wasps and their hosts is low and patchily

24 distributed. Asexuals instead are common in anthropic environments (e.g. grain stores) where host

25 outbreaks offer periods when egg-load is the main constraint on reproductive output.

26 Methods. We present a meta-analysis of known adaptations to these habitats. Differences in

27 behavior, physiology and life-history traits between sexual and asexual wasps were standardized

28 in term of effect size (Cohen's $d$ value, Cohen, 1988).

29 Results. Seeking consilience from the differences between multiple traits, we found that sexuals

30 invest more in longevity at the expense of egg-load, are more mobile, and display higher plasticity

31 in response to thermal variability than asexual counterparts.

32 Discussion. Thus, each form has consistent multiple adaptations to the ecological circumstances

33 in the contrasting environments.

35 Keywords: Local adaptation / Maintenance of sex / Trade-offs / Venturia canescens 


\section{Introduction}

40 Populations of a species from different localities often are locally adapted in life history traits,

41 behavior and physiology (Kraaijeveld \& van Alphen, 1995a; 1995b; Seyahooei et al., 2011a;

42 2011b), but individuals of a species from the same locality tend to have similar traits, because

43 sexual reproduction and recombination prevent the divergence of genotypes. However, local

44 adaptation patterns may differ when an asexual alternative exists. On the one hand, in the same

45 conditions, individuals that reproduce asexually become genetically isolated from the sexual

46 members of the population and thus the sexually reproducing individuals and the asexually

47 reproducing clones could accumulate genetic differences. On the other hand, when sexually

48 reproducing individuals and asexual clones occupy the same niche, normalizing selection would

49 prevent divergence by random drift between sexuals and asexuals.

A variety of processes, including "loss of sexuality" mutations, hybridization and

endosymbiotic infection, cause the occasional generation of asexual strains from sexually reproducing individuals in a range of eukaryotic taxa (Butlin, 2002; Neiman et al., 2014; van der

Kooi \& Schwander, 2014). This phenomenon leads to competition between the newly created asexual strain and the ancestral sexual strain (Lively, 2010; Innes \& Ginn, 2014). When both reproductive modes are obligatory and remain thereafter reproductively isolated, competitive interactions between them could favor individuals of one of the reproductive modes over the other. Asexual individuals, except for their reproductive mode, may differ little in phenotype from their sexual ancestors. Hence, which reproductive mode will be favored depends on the balance between the benefits and costs of sex. These costs result from the inefficiencies of sexual as compared to asexual reproduction (Maynard Smith, 1978; recently reviewed by Lehtonen et al., 2012,

61 Meirmans et al., 2012, and Stelzer, 2015). If environmental conditions enable asexuals to fully 
62 express their reproductive advantages (i.e. the avoidance of mating and of production of male

63 offspring), this mode of reproduction is superior and will replace the sexual form (Maynard Smith, 64 1978).

65 Theoretical studies reveal that coexistence of sexual and asexual competitors is only 66 possible if the newly arisen asexual forms have a smaller inhibitory effect on the sexual forms than

67 the sexual strains have on themselves (Case \& Taper, 1986; Gaggiotti, 1994; Doncaster et al., 68 2000). This may arise when the habitat is structured as a mosaic of environments in which either 69 one or the other form performs better, leading to a potential coexistence at the geographical level 70 (Tilquin \& Kokko, 2016). Asexually reproducing forms are expected to thrive in environments 71 where conditions provide opportunities for reproduction at the maximum possible rate and 72 conditions affecting survival are benign and stable. Sexual forms may resist asexual invasion in 73 environments that are more temporally or spatially heterogeneous, thanks to their higher genetic 74 diversity (Park et al., 2014).

Empirical tests of the hypothesis of coexistence of sexual and asexual forms being mediated by ecological differentiation are lacking (see Letho \& Haag, 2010). Such a test would require (1)

77 a demonstration that the sexually reproducing form differs in habitat use from the asexual form,

78 (2) evidence that the habitat used by the asexually reproducing clones is more benign and/or stable 79 in space and time than that of the sexually reproducing form, regarding factors affecting survival, 80 and (3) that individuals of both reproductive modes are adapted in behavior, physiology and life 81 history traits to their respective habitats.

82 We test the hypothesis of ecological differentiation by bringing together different strands 83 of research in a hymenopteran parasitoid that fits the scenario introduced above. Transitions from 84 sexual reproduction to asexuality have occurred repeatedly and independently in hymenopteran 
85 parasitoids (Godfray, 1994; van Wilgenburg et al., 2006; Heimpel \& de Boer, 2008). In parasitoids,

86 adaptation to different environments is tightly constrained by three main trade-offs (Jervis et al.,

87 2007; 2008; Segoli \& Rosenheim, 2013): 1- allocation to soma (mainly exoskeleton and

88 musculature) versus non-soma (reproductive tissues and gametes, together with initial nutrient reserves); 2- allocation to teneral egg complement versus initial reserves, which is an expression of the classical trade-off between immediate reproduction and survival (for future reproduction); and 3- allocation of resources not assigned to reproduction to either survival or locomotion. The resolution of these trade-offs in different environments should lead to different patterns of adaptation in life-history, as observed, for instance, among populations of Asobara tabida (Kraaijeveld \& van Alphen, 1995a; 1995b) and Leptopilina boulardi (Moiroux et al., 2010; Seyahooei et al., 2011a; 2011b) or in hyperparasitoids Gelis spp. (Visser et al., 2016), but also in behaviors and morphology.

This work aims, through a meta-analysis of life history traits involved in the above mentioned trade-offs, of foraging behavior and morphology to provide an empirical test of the hypothesis of ecological differentiation outlined above using the parasitoid Venturia canescens G.

100 (Hymenoptera: Ichneumonidae).

We chose $V$. canescens for four reasons. First, both reproductive modes are obligatory (i.e. there is no cyclic asexuality) with no known direct benefit of sex such as the formation of resting stages able to resist to harsh environmental conditions (Beukeboom et al., 1999). Second, it is one

104 of the few hymenoptera species where obligate sexual and asexual individuals co-occur and where

105 asexuality is not caused by bacterial endosymbionts (Beukeboom \& Pijnacker 2000; Mateo Leach

106 et al., 2009; Foray et al., 2013b). This characteristic allows us to focus on the ecological factors

107 that impinge on the persistence of both forms independently of the coevolution of the system host- 
108 symbionts (Duron et al., 2008; Werren et al., 2008; Ma et al., 2014). Third, no genetic exchanges

109 through mating occur in natural populations between reproductive modes (Mateo-Leach et al.,

110 2012), preserving different genetic entities and allowing ecological differences. The fourth reason

111 to focus on $V$. canescens is the large number of studies published in the last 17 years providing a

112 wealth of data on the life history and foraging behavior of asexual and sexual forms (Table 1).

113 These studies allow a rich set of comparisons, which have not as yet been exploited to test the 114 pattern of adaptation of each form to its preferential environment (see Meirmans et al., 2012 for a

115 qualitative discussion of some traits). Each of the studies included in our analysis examines a

116 behavioral response in either strain under specific conditions (e.g. exploitation of hosts under

117 changing weather conditions, Amat et al., 2006), or a life-history-trait. The combination of data on

118 a large number of life history and behavioral traits allows us to depict how changes in a whole

119 suite of traits have resulted in adaptation of wasps of both reproductive modes to their respective

120 habitats. Also, our meta-analysis allows assessment of the relative contribution of physiological

121 and behavioral traits and trade-offs to adaption in different environments.

122 Our predictions can be summarized as follows:

123 Life history trade-offs: We expect differences in egg load, survival and flight capability between

124 both forms of $V$. canescens due to the trade-off between current and future reproduction. In natural

125 habitats the majority of individuals are sexuals (asexuals are occasionally found (Schneider et al.,

126 2002; Amat, 2004) but their origin is unknown) exploiting sparsely distributed hosts (Driessen \&

127 Bernstein, 1999). This should favor a higher investment in survival and flight capability for future

128 reproduction at the cost of lower egg production, in comparison to asexuals. The latter live in grain

129 stores and mills, where host distribution is aggregated (Bowditch \& Madden 1996) and the 130 amplitude of host density variation is very large (Campbell \& Arbogast, 2004; Arbogast et al., 
131 2005a; Arbogast et al., 2005b; Belda \& Riudavets, 2013). These environmental conditions should

132 favor higher investment in the production of eggs available for immediate reproduction rather than

133 survival and flight capability. This is consistent with theoretical predictions that heterogeneous

134 distribution of hosts through time and space promotes higher egg production at the expense of

135 other life history traits (Ellers et al., 2000). When finding patches with high host density, animals

136 with higher egg loads could disproportionally contribute to future generations. The trade-off

137 between current and future reproduction could also be influenced by the availability of food

138 sources, which are easily found in the field (Desouhant et al., 2010). Thus, for sexual females, the

139 selective pressure exerted by the hosts for an investment in future reproduction could be

140 counterbalanced by the presence of food, ensuring future reproduction and acting in favor of an

141 investment in immediate reproduction

142 Response to weather conditions: From a behavioral point of view, environmental cues for

143 forthcoming weather changes, such as sudden drops in temperature or atmospheric pressure, can

144 be exploited to adjust foraging or laying behavior, and sensitivity to such cues should be most

145 favored when weather conditions are more unstable, as occurs in natural as compared to storage

146 habitats. For instance, predictable higher mortality during bad weather should promote exploiting

147 host-patches more thoroughly than otherwise (e.g. staying longer or laying pamp eggs; Mangel,

148 1989; Roitberg et al., 1992; Roitberg et al., 1993; Sirot et al., 1997). This behavioural flexibility

149 in sexuals should maintain the fitness value in a wider range of environmental conditions than for

150 asexuals. We expect performance curves, special cases of reaction norms for phenotypic traits

151 related to fitness (fecundity and longevity; Angilletta 2009; Huey and Kingsolver 1989), to be with

152 an optimal value in asexuals (the optimal environmental value at which individuals performance

153 is maximized) and decrease less when moving away from the intermediate temperature in sexuals. 
154 In addition to the behavioral plasticity described above, the reaction norms of physiological or

155 developmental traits also condition the shape of the performance curve

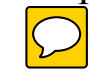

156 Behaviour: Response to intraspecific competition: Female parasitoids compete by superparasitism,

157 i.e. by laying eggs in already parasitized hosts. As this often results in the death of supernumerary

158 larvae (van Alphen \& Visser 1990), fitness returns from oviposition in parasitized hosts are often

159 lower than from ovipositions in unparasitized hosts. Most parasitoid species (including asexual

160 Venturia canescens, Rogers, 1972) mark their hosts with chemicals that inform other females that

161 the host is already parasitized (van Alphen \& Visser, 1990; Marris et al., 1996; Nufio \& Papaj,

162 2001). Thus, females have the information to decide whether or not to lay in an already parasitized

163 host. In natural environments, the encounter rate with hosts is much lower than in grain stores and

164 mills. Hence, sexual wasps being more time limited (high risk of dying before having laid their

165 whole egg-load) should accept parasitized hosts more readily than asexuals do.

\section{Methods}

\section{Biological model:}

Venturia canescens is a solitary (at most a single parasitoid can emerge from a parasitized the hosts). Adults emerge with a stock of mature eggs and continue to produce eggs during their

171 life (Pelosse et al., 2011). Eggs are small and anhydropic (LeRalec 1995), that is without energy

172 reserves. Consequently, the trade-off between egg size and number might not be a strong driver of 173 egg-load evolution.

174 Sexual reproduction in $V$. canescens follows the classical haplo-diploid mechanism of

175 hymenopterans (arrhenotoky): males arise from unfertilized eggs and are haploid, while females 
176 originate from fertilized eggs and are diploid. Sex ratio manipulation has never been observed in

177 this species (Metzger et al., 2008; ED unpublished data) Individuals born through this form of

178 reproduction can be found in natural and semi-natural habitats (e.g. orchards) in the Mediterranean

179 basin, where they parasitize pyralid moth larvae found in dried fruits, following a sparse and 180 uniform distribution (Driessen \& Bernstein, 1999). In field conditions, food sources (sugar-rich

181 substances such as nectar or exudates from fruits) are sufficiently available to allow free foraging

$182 V$. canescens females to maintain a nearly constant level of energetic reserves, at least up to two<smiles>C1=CC2CC1C2</smiles>

183 days(Casas et al., 2003; Desouhant et al., 2010).

184 In contrast, asexual $V$. canescens individuals are produced by automictic thelythoky, a

185 genetically based thelytoky in which meiosis and crossing over occur prior to the restoration of

186 diploidy through the fusion of two pronuclei or of two cleavage nuclei (Beukeboom \& Pijnacker

187 2000). Asexually reproducing $V$. canescens are found throughout Europe and North America

188 (Johnson et al., 2000; Schneider et al., 2002), mainly inside buildings and in association with stored

189 products infested mainly with E. kuehniella, E. cautella (Bowditch \& Madden 1996) or Plodia

190 interpunctella (Roesli et al., 2003, Campbell \& Arbogast, 2004). Food for adults is rarely found in

191 these environments (C. Bernstein, pers. obs.).

\section{Overview and selection of the literature}

The database for the meta-analysis was constituted by using ISI Web of Science (Web of

194 Science Core Collection). We first selected all the papers with the topics "Venturia canescens".

195 Among these papers we selected those with [(thelytok* AND arrhenotok*) OR (sex* AND asex*)]

196 between 1999 (date of the first report of the occurrence of the sexual form in Venturia canescens;

197 Beukeboom et al., 1999) and 2017 (February 10th). Thus, 22 studies, in which different

198 characteristics of asexual and sexual individuals were compared in the laboratory or in the field, 
199 were retained (Figure 1). Then we set apart genetic studies $(n=6)$ from life-history and behavioral 200 studies ( $\mathrm{n}=16$ encompassing 46 traits compared) and focused our analysis on these 16 studies

201 (Tables 1 and 2). Most of the results from the genetic papers (Beukeboom \& Pijnacker, 2000;

202 Schneider et al., 2002; Mateo-Leach et al., 2009; 2012) are treated in our introduction or 203 discussion. We also included unpublished results of one doctoral dissertation (Amat, 2004) (see

204 Figure1). While addressed in the discussion, some results were not included in our meta-analysis; 205 the reasons for each exclusion (in general, for statistical arguments) are given in Supplementary 206 Materials (Appendix A Table 1). Venturia canescens strains involved in our meta-analysis came 207 from 7 localities (Appendix A Table 1) namely Antibes (A and S), Valence (A and S), Mont Boron 208 (A and S), Valbonne (S), Golfe Juan (A), Tuscany (S) and Algarve (S). The most studied strains

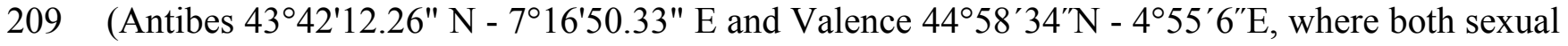
210 and asexual forms are found) were refreshed annually through extensive sampling in the field.

211 Research groups from four European countries were concerned, Czech republic (1 group), 212 Netherlands (2 groups), Deutschland (1 group) and France (2 groups).

213 To assist in interpreting the data, we regrouped the different measures into 8 categories: 214 size, 2 life history traits (fecundity, longevity), 1 physiological character (energy level), 3 215 behavioral characters (flight, competition with conspecifics (superparasitism) and feeding), and 216 capacity to respond to changes in temperature. In each category, several traits are considered and 217 for each of these traits, we obtained 1 to 6 data points from independent studies.

\section{Overview of statistical analyses}

To compare the differences between the two forms for different traits, which by necessity 220 are expressed in different units and have different ranges of variation, we transformed the results

221 to dimensionless (standardized) $d$ effect size measurements (Cohen 1988; Nakagawa \& Cuthill 
222 2007). Cohen (1988) suggested that $d$ values of $0.2,0.5$ and 0.8 could be considered as

223 corresponding to "small", "medium" and "large" biological effects, respectively. Effect sizes are

224 given together with their $95 \%$ confidence intervals. Details of $d$ calculations are presented in the

225 Appendix B. Positive $d$ values correspond to cases where sexuals invest more than asexuals in a

226 category. For superparasitism, positive values imply that hosts already parasitized by sexual

227 females would be more frequently avoided by females irrespective of their reproduntive mode, and 228 reduced patch residence time in response to these encounters by sexuals. About response to 229 temnerature, positive $d$ values imply a relationship trait / temperature steeper concave in asexuals (2)

230 rather than in sexuals.

231

\section{Results}

233 We present the available comparisons in terms of $d$ in Figure 2, and discuss the traits of each

234 category individually below, identifying trait measurement either by the point number of the entry

235 in Figure 2 or by the author's name(s) when the trait cannot been included in Figure 2 (due to

236 statistical or design reasons, see Appendix A Table 1).

237 Fecundity, longevity and size:

238 Figure 2 shows medium to very large effects sizes (meaning large biological differences

239 between forms) for traits likely to affect fecundity. Egg load (points 1-4), number of ovarioles

240 (point 5) and ability to find hosts (at a short distance by walking in an olfactometer, points 6 and

241 8) are all greater in the asexual form. Asexual females are larger than sexual ones even when both

242 are reared in the same host species (points 10-15). 
The large effect size for noint 50 shows that longevity is higher in sexual than asexual $V$.<smiles>C1=CC2CC1C2</smiles>

canescens. The same tendency in found in point 48 , but the confidence intervals for $d$ included the

245 possibility of lack of effect. Barke et al., (2005) considered the difference in longevity between

246 sexual and asexual forms under different temperatures and different levels of food availability.

247 They did not find differences between unfed animals of both forms, but when wasps were fed,

248 sexuals had higher longevity. Their results for $15^{\circ} \mathrm{C}$ are significant, but the data provided do not

249 allow calculating a $d$ value. Points 49 and 47 show the $d$ values for $25^{\circ} \mathrm{C}$ and $29^{\circ} \mathrm{C}$. The confidence

250 intervals for the latter show a lack of effect. On the whole, these data show higher longevity of

251 sexual than asexual forms.

252

253

How differences in fecundity and longevity translate into lifetime reproductive success

254 depends on the environment. In the experimental conditions used by Barke et al., (2005) akin to 255 indoor situations, sexual forms produced a greater lifetime number of offspring (point 44). This 256 result seems unexpected, but under their experimental conditions honey-fed wasps do not need 257 much energy for flying and they can reallocate this energy to fecundity as they are partly 258 synovigenic (i.e. able to mature eggs during their whole lifetime). Moreover, the advantage of 259 asexuals in terms of fecundity remains because daughter production by sexual females is lower 260 than by asexual females. Indeed, even though the offspring sex ratio was not recorded by Barke et 261 al. (2005), Metzger et al., (2008) and Beukeboom (2001) showed that sex ratio was balanced or 262 slightly biased toward females in $V$. canescens. The resolution of the resulting trade-off differs 263 between forms: asexuals invest preferentially in fecundity at the cost of life expectancy, and the 264 opposite occurs in sexual wasps (Pelosse et al., 2007).

\section{Flight:}


A higher investment has been observed under experimental conditions (in the field and in

lab), as evidenced by the small to large effect sizes of the traits belonging to flight category (except

for the null $d$ values obtained for total distance flown and total time in flight during the experiment, points 19 and 20). Flight measurements deserve some additional explanations. As recorded, flight wasps covered similar distances in fewer flights (lower number of rest stops, point 34). Sexual wasps also fly faster (points 35, 38 and 39).

Energy level:

Consistent with their greater dependence on flight, sexual females have higher total metabolic reserves at emergence than asexual ones (point 41). Interestingly, the amount of nutrients not involved in flight show small $d$ values (non-significantly different from 0; proteins: point 25; lipids: points 29 and 28; glucose: points 23 and 24, and free carbohydrates: point 26), but effect size for glycogen reserves are medium to large, with greater glycogen content (at emergence and after flight) in sexual than asexual females (points 51-53). The consumption rates of glycogen (consumption per unit time) do not differ between modes of reproduction (point 27). The results of field experiments are consistent with differences in behavioral and physiological traits found in the laboratory: sexual $V$. canescens initiate dispersal faster after release (point 37) and are less often recaptured in the vicinity of the release point (point 33). Although this could be attributed to

284 the traps being less attractive to sexuals at distance, the result is also consistent with sexuals being 285 more mobile and leaving earlier the release site.

\section{Feeding:}

Differences in initial energy reserves between adults of the two forms can potentially be 
289 same feeding behavior as sexual forms (feeding time and number of feeding bouts per unit of

290 observation time) (points 46 and 9).

291 Response to weather conditions:

292 Sexual, but not asexual, individuals respond to a sudden drop in temperature by exploiting 293 each host-patch more thoroughly (e.g. laying more eggs, point 42, and staying longer). This is 294 consistent with the predicted difference in sensitivity to weather cues. The faster recovering of 295 sexuals from chill coma (point 40) is also indicative of sexuals' higher capability to deal with 296 temperature changes. The lower sensitivity of sexual individuals to temperature changes is also 297 reflected by the large positive $d$ value in point 55 . This point illustrates the higher breadth of 298 temperature during development.

300

Small to medium positive $d$ values for other performance curves or reaction norms,

301 quantifying nutrient contents (protein, lipid, sugar and glycogen: points 30,31, 32 and 45), 302 longevity (point 22), a measure of total fecundity in another study (point 54), fecundity at 303 emergence (point 43) and developmental rate (point 36) according to temperature, indicate a higher

304 tolerance in sexual forms. A measure for longevity yielded a negative value (point 21), but in this

305 case, $d$ did not differ significantly from 0 . In contrast with these results, reaction norms for hind

306 tibia length differed between two studies. Either the two forms express similar curves (point 18)

307 or asexuals show a larger breadth of the curve (point 17). This difference in reaction norms for size

308 was mainly due to differential response at low temperature: lower decrease in size for asexuals

309 when temperature decreases (a similar trend was observed for developmental rate by Foray et al.,

3102014 Appendix A Table 1). Because the relationship between size and fitness varies among insect

311 species (Kazmer \& Luck 1995; West et al., 1996; Ellers et al., 1998) and is unknown in $V$. 
312 canescens, interpreting the adaptive significance of the higher plasticity in size of asexuals remains

313 difficult

314

315 Response to intraspecific competition:

316 The tendency to superparasitize was measured by observing the behavior of females

317 released in host patches previously exploited by sexual or asexual females. Point 7 shows that hosts

318 parasitized by asexual females were more often rejected by other females (independently of their

319 forms) than hosts previously parasitized by sexual females. There was no effect of the reproductive

320 mode of second females on the incidence of superparasitism. Barke et al. (2005), in contrast, found

321 that asexual females had a higher incidence of self-superparasitism. This could be adaptive under

322 circumstances where the probability of conspecific superparasitism is high (Visser et al., 1990).

323 However, their statistical analysis does not seem appropriate to handle random effects (effect of

324 individual females) adequately.

Recognizing parasitized hosts allows females to assess the level of exploitation of a patch.

326 When exploiting partly depleted host patches (i.e. patches in which some hosts are already

327 parasitized), only asexual females decrease patch time (point 16).

329 Discussion

330 The overarching hypothesis under test is that because sexual and asexual forms of Venturia

331 canescens predominate in different ecological scenarios, life-history, anatomical and physiological

332 traits will reflect adaptations to the circumstances of each form. Asexuals proliferate in stores,

333 where hosts are clumped and there is no food for adults, while the hosts of sexual forms tend to be 
334 solitary (one per patch), spatially separated, and occur where food for adult wasps is available.

335 These distinct habitats led us to predict that sexuals should show higher investment in flight

336 capacity, longevity, and ability to tolerate thermal changes, while asexuals will aim at the potential

337 maximum reproductive output conferred by a larger egg-load which they, but not the sexuals, have 338 opportunities to deploy.

\section{Trade-off between current and future reproduction}

Figure 2 displays the outcome of a large number of comparisons, many of which support our overarching hypothesis. Together, these results are clearly consistent with asexuals investing more in fecundity and sexuals more in locomotion and longevity. In environments with a higher rate of host encounter, a higher investment of asexuals in egg load is advantageous. Likewise, the asexual mode of reproduction provides an advantage over sexual lineages by the avoidance of the two-fold cost of sex caused by laying haploid eggs destined to produce males. On the other hand, the higher investment in locomotion and longevity in sexuals matches the host distribution and availability in the field. Facing scarce and spatially scattered hosts, the sexuals may be more often time-limited and die before having laid their whole egg-load. This would select for increased longevity. The effects of time limitation (dying before laying full egg supply) and egg limitation (defined as the temporary or permanent exhaustion of the supply of mature eggs), and how they mediate the trade-off between current and future reproduction, have been explored in various parasitoid species, and are an important aspect of the ecology and evolution of host-parasitoid systems (Rosenheim, 1996; Heimpel et al., 1998; Sevenster et al., 2000; Rosenheim et al., 2008). Contrary to host distribution, the potential high food availability in the field (Casas et al., 2003; Desouhant et al., 2010) could have select for lower initial energy reserves and more nutrients allocated to egg production in sexual wasps.. However, a greater egg load should not be beneficial 
357 in natural conditions due to the low host encounter rate. The balance between these different

358 constraints (hosts and food availability) has favoured a lower investment in egg load and a greater

359 stock of energy in terms of glycogen, that is, the fuel used in $V$. canescens to fly and reach host

360 microhabitats.

361 We cannot rule out that observed differences could result from alternative selective

362 pressures. For instance, the differences in investment in current versus future reproduction could

363 be due to the fact that asexuality may select for lower investment in longevity and energy reserves,

364 as there is no need to spend energy for mate search, courtship and mating. However, $V$. canescens

365 females mate only once, search for hosts and lay eggs just after emergence even if unmated

366 (Metzger et al., 2008; Metzger et al., 2010a). Males search for and encounter females on host

367 patches where mating occurs (Metzger et al., 2010b). That means that saving time and energy from

368 mate search and courtship is anecdotal in the sexual females.

\section{Phenotypic plasticity in response to temperature}

370 Wasps living in natural habitats have more general (breadth) performance curves and are

371 less sensitive to temperature than those living in stores that are specialized to a narrow range of

372 thermal values. Sexual wasps are less affected by temperature in their energy allocation to different

373 functions (e.g. for glycogen, the energetic substrate for flight, Amat et al., 2012); this difference

374 in plasticity may contribute to the difference in the resolution of the trade-off between egg

375 production and survival/locomotion in the two forms of $V$. canescens. However, some of the

376 observed responses may reflect constraints rather than adaptive responses (e.g. for size or

377 developmental rate). In addition to being more plastic, sexual individuals are better able to tolerate

378 extreme temperatures. Only sexual females, which live in variable weather conditions, adjusted

379 their oviposition behavior - increasing their oviposition rate- when experiencing a sudden change 
380 in temperature (Amat et al., 2006). In line with these results, in sexuals, but not in asexuals, there

381 is an accumulation of metabolites with a suspected cryoprotective functions in response to lower

382 temperatures (Foray et al., 2013a; Appendix A Table 1).

383 Superparasitism

384 Sexual females are as efficient as asexual females to discriminate marked from unmarked

385 hosts, and avoid marked ones. However, hosts parasitized by sexual females are less likely to be

386 rejected by later arrivals of either kind than those parasitized by asexuals. Why this is so needs

387 further research, notably since the chemical basis of the recognition has not been studied in sexuals.

388 A possible causal explanation is that there are differences between the marking substances of the

389 two forms, in either composition or quantity, which elicit different responses of later arriving

390 females. Due to the lower probability a host was superparasitized in a short period (beyond 2 days

391 between two successive ovipositions, the first laid larva wins the competition against the second

392 larva, Sirot 1996), sexuals should mark less efficiently the hosts. Another possible functional

393 explanation would be that oviposition into a host already parasitized by a sexual wasps has a higher

394 probability of resulting in an offspring than oviposition into a host previously parasitized by an

395 asexual female (van Alphen \& Visser, 1990; Visser et al., 1992; Sirot 1996). This could be so if

396 asexual larvae show greater aggressiveness than sexual ones when fighting inside the

397 superparasitzed host. While deserving further attention, results of Amat (2004) suggested such an

398 asymmetry in competitive abilities of sexuals and asexuals in superparasitized larvae (for short

399 time intervals between successive ovipositions).

400 Differences in superparasitism rate between sexuals and asexuals may also be increased by kin

401 selection. Under the hypothesis that asexuals are genetically close, avoidance of superparasitism

402 in anthropogenic conditions would be expected. This hypothesis needs extra works to be tested. 
404

405

406

407

408

409

410

411

412

413

414

415

416

417

418

420

421

422

424

425

Cognitive abilities

Additionally, some studies considered the differences in cognitive abilities between sexuals and asexuals (learning color or odor cues related to resource availability, and time to take a decision in choice experiments) (Thiel et al., 2006; Lucchetta et al., 2007; 2008; Liu et al., 2009a and Thiel et al., 2013 in Appendix A Table 1). Thriving in a more complex environment, sexuals are expected to benefit more than asexuals from being efficient at locating hosts and at learning local conditions (Stephens, 1993). In most cases, the results were presented in terms of statistics not suitable to be expressed into $d$ values or reproductive mode is involved in higher-level interactions that impede to interpret its additive effect. These results cannot be incorporated to Figure 2 and compared to other results.

\section{Origin of differences between forms}

The consilience between observations on different biological dimensions do confirm the hypothesis that the two reproductive forms (sexual and asexual) of Venturia canescens are adapted to the different ecological niches in which these forms are typically found. However, the origin of the differences between the 2 forms and notably, whether the loss of sex is secondary or preexisting to the invasion of storage sites remains unknown. Nevertheless, the probably rare occurrence of asexuality, the absence of genetic exchange between forms (that can be inferred from the complete separation of the two forms according to the nuclear marker composition) and the low genetic variability of asexual females may impede their adaptability (Mateo Leach et al., 2012). For this reason, the scenario under which asexual females would have evolved all the observed adaptations (following the invasion of storage sites or just as a consequence of their asexuality) seems unlikely. A more plausible evolutionary trajectory is that loss of sexuality 
426 occurred after invasion of stores, and that it forms further adaptation to the benign and stable

427 conditions encountered therein, as well as increased egg load or reduced energy reserves. An 428 analysis of the evolutionary routes of both reproductive modes would allow distinguishing these 429 scenarios.

430 Coexistence of sexuals and asexuals through ecological differentiation

431 Understanding the paradoxical coexistence of sexuals and asexuals requires quantifying the

432 balance between costs and benefits of sex via a species-specific approach (Stelzer 2015, Meirmans 433 et al., 2012). Three main factors influence this equilibrium: constraints on evolution of asexuality, 434 ecological differentiation and life-history traits (Meirmans et al., 2012). Our results strongly 435 suggest that ecological differentiation may be a corner-stone to coexistence of the sexuals and 436 asexuals forms in Venturia canescens. Our conclusion is congruent with previous studies reporting, 437 in several taxa, differences in habitat preferences and in responses to environmental conditions 438 between closely related sexual and asexual strains: in plants (dandelions, Meirmans et al., 2012), 439 insects (aphids, Simon et al., 2002, Gilabert et al., 2014), crustacean (Rossi et al., 2016) and fish 440 (Schenck \& Vrijenhoek 1986). Nevertheless, to firmly conclude about the involvement of

441 ecological differentiation on coexistence of both reproductive modes in $V$. canescens, further

442 investigations are needed to experimentally test, as done by Letho and Haag (2010) in Daphnia 443 pulex, whether the relative fitness of the sexual and asexual wasps depends on ecological 444 conditions, that is, whether sexuals outperform asexuals in the field and asexuals outperform 445 sexuals in building conditions.

\section{Conclusions}


447 Our comparison of life history traits between the two modes of reproduction in $V$. canescens shows

448 that sexual and asexual individuals are each better adapted to the ecological niches which they 449 occupy in a whole suit of characters. This conclusion is strengthened by the consistency between 450 multiple observed differences, which are in accordance with the inferred selective pressures in 451 both habitats. The life history traits that show the strongest relative divergences (high absolute 452 values of $d$ in Figure 2) are those involved in the trade-off between egg load and adult survival or 453 locomotion, and in the phenotypic plasticity in response to temperature. The consistency of the 454 effect sizes obtained with individuals of both reproductive forms originating from different 455 localities is a sound indication of their generality. 


\section{References}

458 Amat I. 2004. Coexistence de la reproduction sexuée et asexuée chez l'hyménoptère parasitoïde

459 Venturia canescens : aspects comportementaux et écologiques. Ph.D. Dissertation. Université

460 Claude Bernard - Lyon 1.

461 Amat I, Castelo M, Desouhant E, Bernstein C. 2006. The influence of temperature and host

462 availability on the host exploitation strategies of sexual and asexual parasitic wasps of the same

463 species. Oecologia 148:153-61.

464 Amat I, Desouhant E, Bernstein C. 2009. Differential use of conspecific-derived information

465 by sexual and asexual parasitic wasps exploiting partially depleted host patches. Behav. Ecol.

466 Sociobiol. 63:563-572.

467 Amat I, Besnard S, Foray V, Pelosse P, Bernstein C, Desouhant E. 2012. Fuelling flight in a 468 parasitic wasp: which energetic substrate to use? Ecol. Entomol. 37:480-489.

469 Angilletta MJ. 2009. Thermal adaptation: a theoretical and empirical synthesis. University 470 Press, Oxford.

471 Arbogast RT, Chini SR. 2005a. Abundance of Plodia interpunctella (Hübner) and Cadra 472 cautella (Walker) infesting maize stored on South Carolina farms: Seasonal and non-seasonal 473 variation. J. Stored Prod. Res. 41:528-543.

474 Arbogast RT, Chini SR, Kendra PE. 2005b. Infestation of stored saw palmetto berries by Cadra 475 cautella (Lepidoptera: Pyralidae) and the Host Paradox in Stored-Product Insects. Florida 476 Entomol. 88:314-320.

477 Barke J, Mateo Leach I, Beukeboom LW. 2005. Fitness of arrhenotokous and thelytokous 478 Venturia canescens. Proc. Sect. Exp. Appl. Entomol. Netherlands Entomol. Soc. 16:27-35. 
Belda C, Riudavets J. 2013. Natural enemies associated with lepidopteran pests in food and 480 feed processing companies. J. Stored Prod. Res. 53:54-60.

481 Beukeboom LW, Driessen G, Luckerhoff L. 1999. Distribution and relatedness of sexual and 482 asexual Venturia canescens (Hymenoptera). Proc. Sect. Exp. Appl. Entomol. Netherlands 483 Entomol. Soc. 10:23-28.

484 Beukeboom LW, Pijnacker LP. 2000. Automictic parthenogenesis in the parasitoid Venturia 485 canescens (Hymenoptera: Ichneumonidae) revisited. Genome 43:939-944.

486 Beukeboom LW. 2001. Single-locus complementary sex determination in the Ichneumonid 487 Venturia canescens (Gravenhorst) (Hymenoptera). Netherlands J. Zool. 51:1-15.

488 Bowditch TG, Madden TL. 1996. Spatial and temporal distribution of Ephestia cautella 489 (Walker) (Lepidoptera: Pyralidae) in a confectionary factory: causal factors and management 490 implications. J. Stored Prod. Res. 32:123-130.

491 Butlin R. 2002. Evolution of sex: the costs and benefits of sex: new insights from old asexual 492 lineages. Nat. Rev. Genet. 3:311-317.

493 Campbell JF, Arbogast RT. 2004. Stored-product insects in a flour mill: Population dynamics 494 and response to fumigation treatments. Entomol. Exp. Appl. 112:217-225.

495 Casas J, Driessen G, Mandon N, Wielaard S, Desouhant E, van Alphen J, Lapchin L, Rivero A, 496 Christides JP, Bernstein C. 2003. Energy dynamics in a parasitoid foraging in the wild. J. Anim. 497 Ecol. 72:691-697.

498 Case T, Taper M. 1986. On the coexistence and coevolution of asexual and sexual competitors. 499 Evolution. 40:366-387. 
500 Cohen J. 1988. Statistical Power Analysis for the Behavioural Sciences $2^{\text {nd }}$ edition. Hillsdale,

501 NJ: Erlbaum.

502 Desouhant E, Lucchetta P, Giron D, Bernstein C. 2010. Feeding activity pattern in a parasitic 503 wasp when foraging in the field. Ecol. Res. 25:419-428.

504 Doncaster CP, Pound GE, Cox SJ. 2000. The ecological cost of sex. Nature 404:281-285.

505 Driessen G, Bernstein C. 1999. Patch departure mechanisms and optimal host exploitation in 506 an insect parasitoid. J. Anim. Ecol. 68:445-459.

507 Duron O, Bouchon D, Boutin S, Bellamy L, Zhou L, Engelstadter J, Hurst GD. 2008. The 508 diversity of reproductive parasites among arthropods: Wolbachia do not walk alone. BMC Biol. $5096: 27$.

510 Ellers J, van Alphen JJM, Sevenster JG. 1998. A field study of size-fitness relationships in the 511 parasitoid Asobara tabida. J. Anim. Ecol. 67:318-324.

512 Ellers J, Sevenster JG, Driessen G. 2000. Egg load evolution in parasitoids. Am. Nat. 156:650513665.

514 Foray V, Gibert P, Desouhant E. 2011. Differential thermal performance curves in response to 515 different habitats in the parasitoid Venturia canescens. Naturwissenschaften 98:683-91.

516 Foray V, Desouhant E, Voituron Y, Larvor V, Renault D, Colinet H, Gibert P. 2013a. Does 517 cold tolerance plasticity correlate with the thermal environment and metabolic profiles of a 518 parasitoid wasp? Comp. Biochem. Physiol. A. Mol. Integr. Physiol. 164:77-83.

519 Foray V, Henri H, Martinez S, Gibert P, Desouhant E. 2013b. Occurence of arrhenotoky and 520 thelytoky in a parasitic wasp Venturia canescens (Hymenoptera: Ichneumonidae): Effect of 521 endosymbionts or existence of two distinct reproductive modes? Eur. J. Entomol. 110:103-107. 
522 Foray V, Desouhant E, Gibert P. 2014. The impact of thermal fluctuations on reaction norms

523 in specialist and generalist parasitic wasps. Funct. Ecol. 28:411-423.

524 Gaggiotti OE. 1994. An ecological model for the maintenance of sex and geographic 525 parthenogenesis. J. Theor. Biol. 167:201-221.

526 Gilabert A, Simon JC, Dedryver CA, Plantegenest M. 2014. Do ecological niches differ 527 between sexual and asexual lineages of an aphid species? Evol. Ecol. 28:1095-1104.

528 Godfray HCJ. 1994. Parasitoids: Behavioural and Evolutionary Ecology. Princeton, NJ: 529 Princeton University Press.

530 Harrison JF, Roberts SP. 2000. Flight respiration and energetics. Annu. Rev. Physiol. 62:179531205.

532 Heimpel GE, Mangel M, Rosenheim JA. 1998. Effects of time limitation and egg limitation on 533 lifetime reproductive success of a parasitoid in the field. Am. Nat. 152:273-289.

534 Heimpel GE, de Boer JG. 2008. Sex determination in the hymenoptera. Annu. Rev. Entomol. $535 \quad 53: 209-30$.

536 Huey RB, Kingsolver JG. 1989. Evolution of thermal sensitivity of ectotherm performance. 537 Trends Ecol. Evol. 4:131-135.

538 Hunter JE, Schmidt FL. 2004. Methods of Meta-Analysis: Correcting Error and Bias in 539 Research Finding, 2nd edition. Thousand Oaks, CA: Sage.

540 Innes DJ, Ginn M. 2014. A population of sexual Daphnia pulex resists invasion by asexual 541 clones. Proc. R. Soc. B 281:20140564. 
542 Jervis MA, Boggs CL, Ferns PN. 2007. Egg maturation strategy and survival trade-offs in

543 holometabolous insects: A comparative approach. Biol. J. Linn. Soc. 90:293-302.

544 Jervis MA, Ellers J, Harvey JA. 2008. Resource acquisition, allocation, and utilization in 545 parasitoid reproductive strategies. Annu. Rev. Entomol. 53:361-85.

546 Johnson JA, Valero KA, Hannel MM, Gill RF. 2000. Seasonal occurrence of postharvest dried

547 fruit insects and their parasitoids in a culled fig warehouse. J. Econ. Entomol. 93:1380-1390.

548 Kazmer DJ, Luck RF. 1995. Field tests of the size-fitness hypothesis in the egg parasitoid 549 Trichogramma pretosium. Ecology 76:412-425.

550 Kraaijeveld AR, van Alphen JJM. 1995. Geographical variation in encapsulation ability of 551 Drosophila melanogaster larvae and evidence for parasitoid-specific components. Evol. Ecol. $5529: 10-17$.

553 Kraaijeveld AR, van Alphen JJM. 1995. Variation in diapause and sex ratio in the parasitoid 554 Asobara tabida. Entomol. Exp. Appl. 74:259-265.

555 Lehtonen J, Jennions MD, Kokko H. 2012. The many costs of sex. Trends Ecol. Evol. 27:172-8.

556 Lehto MP, Haag CR. 2010. Ecological differentiation between coexisting sexual and asexual 557 strains of Daphnia pulex. J. Anim. Ecol. 79:1241-1250.

558 Liu YQ, Bernstein C, Thiel A. 2009a. Travel duration, energetic expenditure, and patch 559 exploitation in the parasitic wasp Venturia canescens. Behav. Ecol. Sociobiol. 63:1459-1469.

560 Liu YQ, Thiel A, Hoffmeister TS. 2009b. Odor-mediated patch choice in the parasitoid 561 Venturia canescens: Temporal decision dynamics. Entomol. Exp. Appl. 132:110-117. 
562 Lively CM. 2010. A review of red queen models for the persistence of obligate sexual

563 reproduction. J. Hered. 101:13-20.

564 Lucchetta P, Desouhant E, Wajnberg E, Bernstein C. 2007. Small but smart: the interaction

565 between environmental cues and internal state modulates host-patch exploitation in a parasitic

566 wasp. Behav. Ecol. Sociobiol. 61:1409-1418.

567 Lucchetta P, Bernstein C, Théry M, Lazzari C, Desouhant E. 2008. Foraging and associative

568 learning of visual signals in a parasitic wasp. Anim. Cogn. 11:525-33.

569 Lukáš J, Bernstein C, Gu H, Dorn S. 2010. Could different environmental conditions select for 570 different flight characteristics in sexual and asexual parasitoid Venturia canescens? Entomol. Exp. 571 Appl. 136:80-88.

572 Ma WJ, Vavre F, Beukeboom LW. 2014. Manipulation of arthropod sex determination by 573 endosymbionts: Diversity and molecular mechanisms. Sex. Dev. 8:59-73.

574 Mangel M. 1989. Evolution of host selection in parasitoids: Does the state of the parasitoid 575 matter? Am. Nat. 133:688-705.

576 Marris GC, Hubbard SF, Scrimgeour C. 1996. The perception of genetic similarity by the 577 solitary parthenogenetic parasitoid Venturia canescens, and its effects on the occurrence of 578 superparasitism. Entomol. Exp. Appl. 78:167-174.

579 Mateo Leach I, Hesseling A, Huibers WHC, Witsenboer H, Beukeboom LW, van de Zande L. 580 2009. Transcriptome and proteome analysis of ovaries of arrhenotokous and thelytokous Venturia 581 canescens. Insect Mol. Biol. 18:477-82.

582 Mateo Leach I, Ferber S, van de Zande L, Beukeboom LW. 2012. Genetic variability of 583 arrhenotokous and thelytokous Venturia canescens (Hymenoptera). Genetica 140:53-63. 
Maynard Smith J. 1978. The evolution of sex. Cambridge, UK: Cambrige University Press.

Meirmans S, Meirmans PG, Kirkendall LR. 2012. The costs of sex: facing real-world complexities. Q. Rev. Biol. 87:19-40.

Metzger M, Bernstein C, Desouhant E. 2008. Does constrained oviposition influence offspring 588 sex ratio in the solitary parasitoid wasp Venturia canescens? Ecol. Entomol. 33:167-174.

Metzger M, Bernstein C, Hoffmeister TS, Desouhant E. 2010. Does kin recognition and sibmating avoidance limit the risk of genetic incompatibility in a parasitic wasp? PloS one 5:e13505.

Moher D, Liberati A, Tetzlaff J, Altman DG, The PRISMA Group (2009). Preferred Reporting Items for Systematic Reviews and Meta-Analyses: The PRISMA Statement. PLoS Med 6(7): 593 e1000097.

Moiroux J, Le Lann C, Seyahooei MA, Vernon P, Pierre JS, van Baaren J, van Alphen JJM. 595 2010. Local adaptations of life-history traits of a Drosophila parasitoid, Leptopilina boulardi: Does climate drive evolution? Ecol. Entomol. 35:727-736.

Nakagawa S, Cuthill IC. 2007. Effect size, confidence interval and statistical significance: a 598 practical guide for biologists. Biol. Rev. 82:591-605.

Neiman M, Sharbel TF, Schwander T. 2014. Genetic causes of transitions from sexual 600 reproduction to asexuality in plants and animals. J. Evol. Biol. 27:1346-59.

Nufio CR, Papaj DR. 2001. Host marking behavior in phytophagous insects and parasitoids.

602 Entomol. Exp. Appl. 99:273-293.

603 Park AW, Vandekerkhove J, Michalakis Y. 2014. Sex in an uncertain world: Environmental 604 stochasticity helps restore competitive balance between sexually and asexually reproducing 605 populations. J. Evol. Biol. 27:1650-1661. 
606 Pelosse P, Bernstein C, Desouhant E. 2007. Differential energy allocation as an adaptation to 607 different habitats in the parasitic wasp Venturia canescens. Evol. Ecol. 21:669-685.

608 Pelosse P, Amat I, Bernstein C, Desouhant E. 2010. The dynamics of energy allocation in adult 609 arrhenotokous and thelytokous Venturia canescens. Entomol. Exp. Appl. 135:68-76.

610 Pelosse P, Jervis MA, Bernstein C, Desouhant E. 2011. Does synovigeny confer reproductive 611 plasticity upon a parasitoid wasp that is faced with variability in habitat richness? Biol. J. Linnean 612 Soc. 104:621-632.

613 Roesli R, Subramanyam B, Campbell JF, Kemp K. 2003. Stored-product insects associated with 614 a retail pet store chain in Kansas. J. Econ. Entomol. 96:1958-66.

615 Rogers D. 1972. The ichneumon wasp Venturia canescens: oviposition and avoidance of 616 superparasitism. Entomol. Exp. Appl. 5:190-94

617 Roitberg BD, Mangel M, Lalonde RG, Roitberg CA, van Alphen JJM, Vet L. 1992. Seasonal 618 dynamic shifts in patch exploitation by parasitic wasps. Behav. Ecol. 3:156-165.

619 Roitberg BD, Sircom J, Roitberg CA, van Alphen JJM, Mangel M. 1993. Life expectancy and 620 reproduction. Nature 364:108.

621 Rosenheim JA. 1996. An evolutionary argument for egg limitation. Evolution 50:2089-2094.

622 Rosenheim JA, Jepsen SJ, Matthews CE, Smith DS, Rosenheim MR. 2008. Time limitation, 623 egg limitation, the cost of oviposition, and lifetime reproduction by an insect in nature. Am. Nat. 624 172:486-96.

625 Salt G. 1976. The hosts of Nemeritis canescens a problem in the host specificity of insect 626 parasitoids. Ecol. Entomol. 1:63-67. 
627 Schenck, RA, Vrijenhoek, RC 1986. Spatial and temporal factors affecting coexistence among P

628 sexual and clonal forms of Poeciliopsis. Evolution 40: 1060-1070.

629 Schneider MV, Beukeboom LW, Driessen G, Lapchin L, Bernstein C, van Alphen JJM. 2002.

630 Geographical distribution and genetic relatedness of sympatrical thelytokous and arrhenotokous

631 populations of the parasitoid Venturia canescens (Hymenoptera). J. Evol. Biol. 15:191-200.

632 Segoli M, Rosenheim JA. 2013. The link between host density and egg production in a 633 parasitoid insect: comparison between agricultural and natural habitats. Funct. Ecol. 27:11246341232.

635 Sevenster JG, Ellers J, Driessen G. 2000. An evolutionary argument for time limitation. Am. 636 Nat. 52:1241-1244

637 Seyahooei MA, van Alphen JJM, Kraaijeveld K. 2011. Metabolic rate affects adult life span 638 independently of developmental rate in parasitoid wasps. Biol. J. Linn. Soc. 103:45-56.

639 Seyahooei MA, van Alphen JJM, Kraaijeveld K. 2011. Genetic structure of Leptopilina 640 boulardi populations from different climatic zones of Iran. BMC Ecol. 11:4.

641 Simon JC, Rispe C, Sunnucks P. 2002. Ecology and evolution of sex in aphids. Trends Ecol. 642 Evol. 17: 34-39.

643 Sirot E. 1996. The pay-off from superparasitismin the solitary parasitoid Venturia canescens. 644 Ecol. Entomol. 21:305-307.

645 Sirot E, Ploye H, Bernstein C. 1997. State dependent superparasitism in a solitary parasitoid : 646 egg load and survival. Behav. Ecol. 8:226-232.

647 Stelzer CP. 2015. Does the avoidance of sexual costs increase fitness in asexual invaders? Proc. 648 Natl. Acad. Sci. 112:201501726. 
649 Stephens DW. 1993. Learning and behavioral ecology: incomplete information and 650 environmental predictability. In Papaj DR, Lewis AC, editors. Insect learning: ecological and 651 evolutionary perspectives. New York, NY: Chapman \& Hall. p. 195-218.

652 Thiel A, Driessen G, Hoffmeister T. 2006. Different habitats, different habits? Response to 653 foraging information in the parasitic wasp Venturia canescens. Behav. Ecol. Sociobiol. 59:614654623.

655 Thiel A, Schlake S, Kosior D. 2013. Omnia tempus habent: Habitat-specific differences in 656 olfactory learning and decision making in parasitic wasps. Anim. Cogn. 16:223-232.

657 Tilquin A, Kokko H. 2016. What does the geography of parthenogenesis teach us about sex? 658 Philos. Trans. R. Soc. Lond. B. Biol. Sci. 371:20150516-20150538.

659 van Alphen JJM, Visser ME. 1990. Superparasitism as an adaptive strategy for insect 660 parasitoids. Annu. Rev. Entomol. 35:59-79.

661 van der Kooi CJ, Schwander T. 2014. Evolution of asexuality via different mechanisms in grass 662 thrips (Thysanoptera: Aptinothrips). Evolution (68:1883-1893.

663 van Wilgenburg E, Driessen G, Beukeboom LW. 2006. Single locus complementary sex 664 determination in Hymenoptera: an "unintelligent” design? Front. Zool. 3:1-15.

665 Visser B, Le Lann C, Snaas H, Verdeny-Vilalta O, Harvey JA. 2016. Divergent life history 666 strategies in congeneric hyperparasitoids. Evol. Ecol. 30:535-549.

667 Visser ME, van Alphen JJM, Nell HW. 1990. Adaptive superparasitism and patch time 668 allocation in solitary parasitoids - the influence of the number of parasitoids depleting a patch. 669 Behaviour 114: 21-36. 
670 Visser ME, Luyckx B, Nell HW, Boskamp GJF. 1992. Adaptive superparasitism in solitary 671 parasitoids: marking of parasitized hosts in relation to the pay-off from superparasitism. Ecol. 672 Entomol. 17:76-82.

673 Werren JH, Baldo L, Clark ME. 2008. Wolbachia: master manipulators of invertebrate biology. 674 Nature Rev. Microbiol. 6:741-751.

675 West SA, Flanagan KE, Godfray HCJ. 1996. The relationship between parasitoid size and 676 fitness in the field, a study of Achrysocharoides zwoelferi (Hymenoptera: Eulophidae). J. Anim. 677 Ecol. 65: 631-639.

678 


\section{Legend}

680 Figure 1. PRISMA flow Diagram describing the process of literature selection (from Moher et al., $6812009)$

682

683 Figure 2.

684 Standardized coefficients (Cohen's $d$ ) $\pm 95 \%$ confidence intervals for the difference between 685 asexual and sexual $V$. canescens. The traits under study were pooled into eight categories (size, 686 fecundity, longevity, energy reserve, flight ability, feeding behavior, superparasitism, and 687 response to temperature changes). Positive $d$ values indicate higher investment by sexual animals. 688 When dealing with reaction norms $(\mathrm{RN})$ or performance curves (points 17-18, 21-22, 30-32, 36, 68943,45 and 54-55), positive $d$ values stand for less concave curve shape in sexuals). Blue shades 690 stand for categories where sexuals are expected to invest more than asexuals: longevity, energy, 691 flight and response to temperature changes. Red shades stand for categories where asexuals are 692 expected to invest more than sexuals: fecundity and use of conspecific information in the context 693 of superparasitism. Purple shades are used for size and feeding behavior for which no clear 694 predictions could be made. A black vertical line at $d=0$ indicates lack of statistical significance, 695 and grey vertical lines at $d=0.2(-0.2), 0.5(-0.5)$ and $0.8(-0.8)$ indicate values over (below) which 696 the difference is deemed "small" (S), "medium" (M) and "large" (L) (Nakagawa \& Cuthill, 2007). 697 Measures whose confidence intervals overlap 0 were figured in grey. See Table 1 for each point 698 description and authority. Points are figured by ascending order of mean of the traits. When 699 multiple studies recorded data on the same trait, the trait is labeled only once. 
$701 \quad$ Figure 1

702

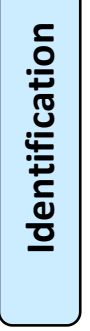

Records identified through database searching

$(n=22)$

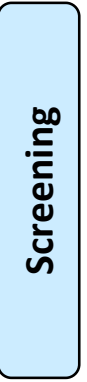

Records after duplicates removed

$$
(n=23)
$$

Additional records identified through other sources

$(n=1)$
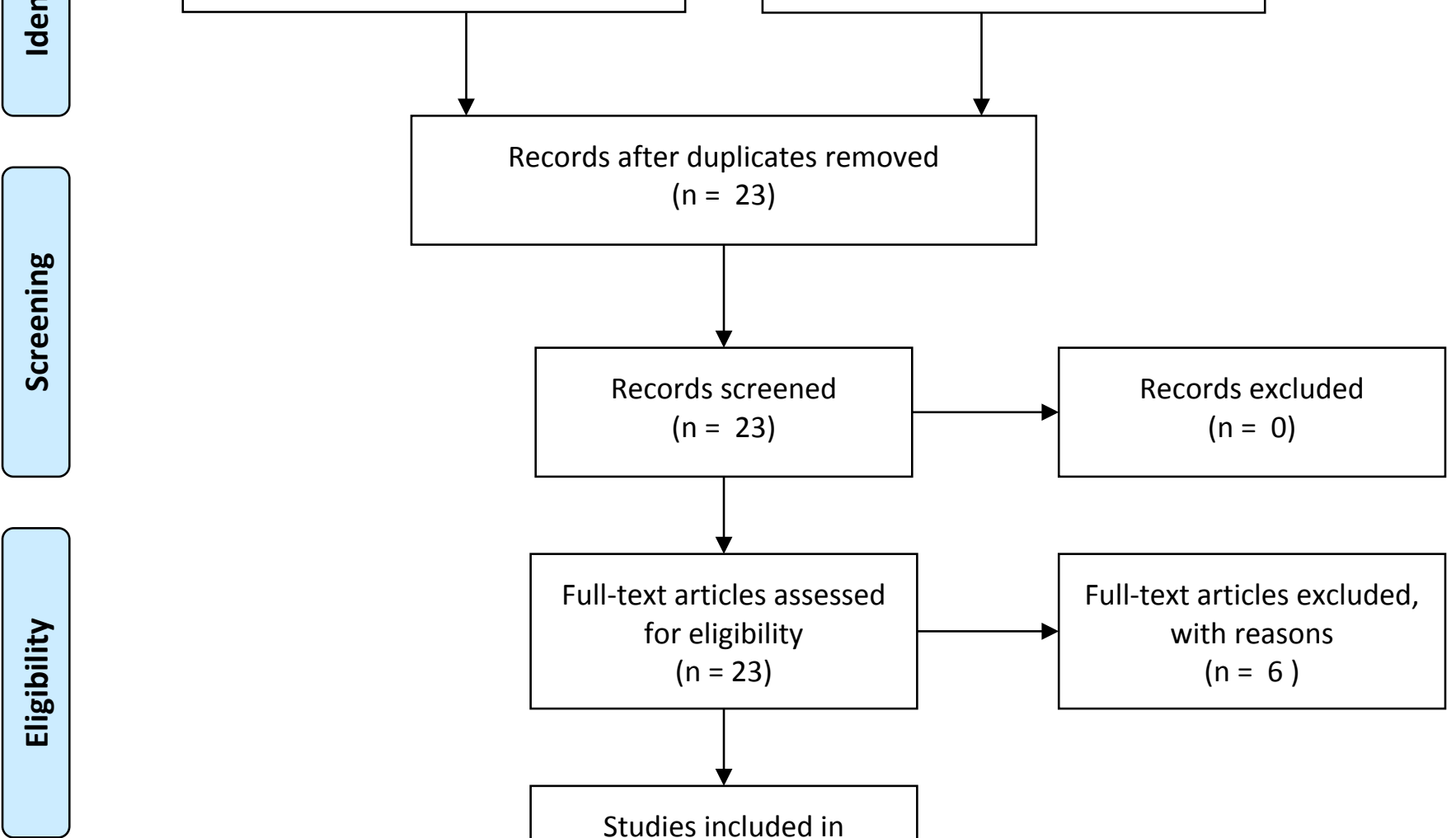

웜

Studies included in qualitative synthesis $(n=17)$

Studies included in quantitative synthesis (meta-analysis)

$(n=17)$ 


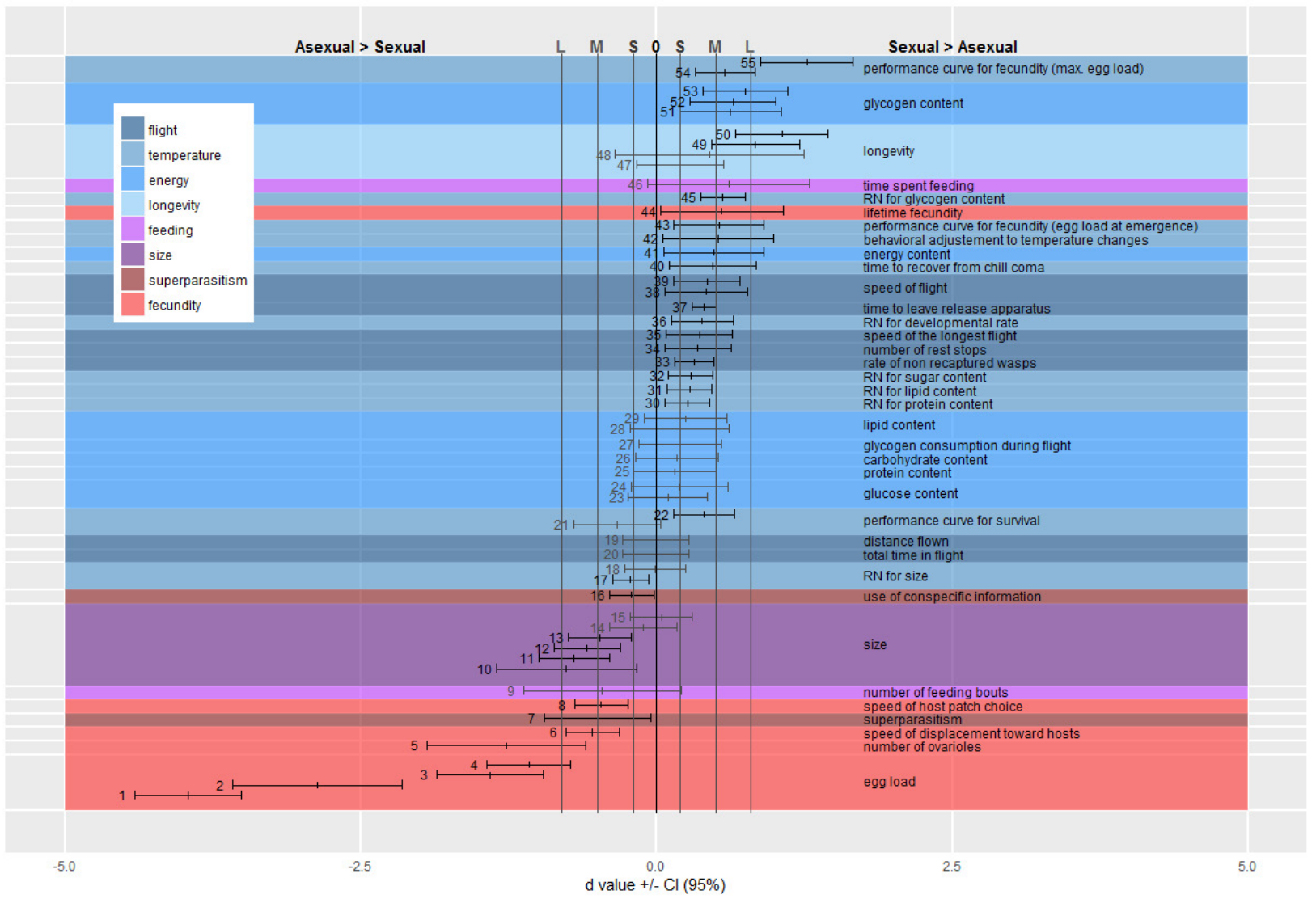


706 Table 1

707 Authors and trait under comparison between sexual and asexual strains included in Figure 2 and

708 figures in the original article showing specific results. Category represents the 8 categories of

709 measures we defined: size, 2 life history traits (Fecundity, Longevity), 1 physiological character

710 (Energy level), 3 behaviors (Flight, Superparasitism and Feeding) and 1 response to temperature

711 change (Temperature); these categories referred also to those used in Figure 2. Data from this table

712 were obtained using strains collected at two different locations in France: in the vicinity of Antibes

713 (Ant), and Valence (Val) and yearly renewed with freshly caught individuals.

\begin{tabular}{|c|c|c|c|c|c|}
\hline Authors & $\begin{array}{l}\text { Trait under comparison between } \\
\text { sexual and asexual } V \text {. canescens }\end{array}$ & $\begin{array}{l}\text { origin of the } \\
\text { strains }\end{array}$ & $\begin{array}{l}\text { Figures in } \\
\text { original paper }\end{array}$ & $\begin{array}{c}\text { Point } \\
\text { number in } \\
\text { Fig. } 2\end{array}$ & Category \\
\hline $\begin{array}{l}\text { Amat et al., } \\
(2012)\end{array}$ & Egg-load at emergence; & Val & $1 \mathrm{c}$ & 1 & Fecundity \\
\hline $\begin{array}{l}\text { Barke et al., } \\
(2005)\end{array}$ & Egg-load at emergence & Ant & 7.4 & 2 & Fecundity \\
\hline $\begin{array}{l}\text { Pelosse et al., } \\
\text { (2007) }\end{array}$ & Egg-load at emergence & Val & & 3 & Fecundity \\
\hline $\begin{array}{l}\text { Pelosse et al., } \\
(2010)\end{array}$ & Egg-load at emergence & Val & 1 & 4 & Fecundity \\
\hline $\begin{array}{l}\text { Barke et al., } \\
(2005)\end{array}$ & Number of ovarioles & Ant & 7.5 & 5 & Fecundity \\
\hline $\begin{array}{l}\text { Liu et al., } \\
(2009 b)\end{array}$ & Time to respond host odor & Val, Ant & 1,2 & 6 & Fecundity \\
\hline
\end{tabular}




\begin{tabular}{|c|c|c|c|c|c|}
\hline $\begin{array}{l}\text { Amat et al., } \\
\text { (2009) }\end{array}$ & $\begin{array}{l}\text { Host propensity to be avoided for } \\
\text { superparasitism }\end{array}$ & Ant & 1 & 7 & $\begin{array}{c}\text { Superpara } \\
\text { sitism }\end{array}$ \\
\hline $\begin{array}{l}\text { Liu et al., } \\
\text { (2009b) }\end{array}$ & $\begin{array}{l}\text { Time to choose host patches differing } \\
\text { in their quality }\end{array}$ & Val, Ant & 1,2 & 8 & Fecundity \\
\hline $\begin{array}{l}\text { Pelosse et al., } \\
\text { (2010) }\end{array}$ & Number feeding bouts & Val & & 9 & Feeding \\
\hline $\begin{array}{l}\text { Pelosse et al., } \\
\text { (2010) }\end{array}$ & Hind tibia length & Val & & 10 & Size \\
\hline $\begin{array}{l}\text { Amat } \\
(2004)\end{array}$ & Hind-tibia length & Ant & & 11 & Size \\
\hline $\begin{array}{l}\text { Lukas et al., } \\
\text { (2010) }\end{array}$ & Hind tibia length & Val & & 12 & Size \\
\hline $\begin{array}{l}\text { Amat et al., } \\
\text { (2012) }\end{array}$ & Hind-tibia length & Val & $1 \mathrm{a}, \mathrm{b}$ & 13 & Size \\
\hline $\begin{array}{l}\text { Pelosse et al., } \\
\text { (2007) }\end{array}$ & Hind tibia length & Val & & 14 & Size \\
\hline $\begin{array}{l}\text { Foray et al., } \\
\text { (2011) }\end{array}$ & Hind tibia length & Val & 1a & 15 & Size \\
\hline $\begin{array}{l}\text { Amat et al., } \\
\text { (2009) }\end{array}$ & $\begin{array}{l}\text { Patch residence time in response to } \\
\text { ovipositions in parasitized hosts }\end{array}$ & Ant & & 16 & $\begin{array}{c}\text { Superpara } \\
\text { sitism }\end{array}$ \\
\hline $\begin{array}{l}\text { Foray et al., } \\
(2014)\end{array}$ & $\begin{array}{l}\text { Reaction norm for hind tibia length at } \\
\text { different temperatures }\end{array}$ & Val & $2 \mathrm{a}$ & 17 & $\begin{array}{c}\text { Temperat } \\
\text { ure }\end{array}$ \\
\hline $\begin{array}{l}\text { Foray et al., } \\
\text { (2011) }\end{array}$ & $\begin{array}{l}\text { Reaction norm for hind tibia length as a } \\
\text { function of temperature }\end{array}$ & Val & 1a & 18 & $\begin{array}{c}\text { Temperat } \\
\text { ure }\end{array}$ \\
\hline
\end{tabular}




\begin{tabular}{|c|c|c|c|c|c|}
\hline $\begin{array}{l}\text { Lukas et al., } \\
(2010)\end{array}$ & $\begin{array}{l}\text { Total distance flown and total time in } \\
\text { flight }\end{array}$ & Val & & 19,20 & Flight \\
\hline $\begin{array}{l}\text { Foray et al., } \\
\text { (2011) }\end{array}$ & $\begin{array}{l}\text { Performance curve for longevity as a } \\
\text { function of temperature }\end{array}$ & Val & 2 & 21 & $\begin{array}{c}\text { Temperat } \\
\text { ure }\end{array}$ \\
\hline $\begin{array}{l}\text { Foray et al., } \\
\text { (2014) }\end{array}$ & $\begin{array}{l}\text { Performance curve for longevity at } \\
\text { different temperatures }\end{array}$ & Val & $3 \mathrm{c}$ & 22 & $\begin{array}{c}\text { Temperat } \\
\text { ure }\end{array}$ \\
\hline $\begin{array}{l}\text { Pelosse et al., } \\
\text { (2010) }\end{array}$ & Glucose content & Val & $2 a, b$ & 23 & $\begin{array}{l}\text { Energy } \\
\text { level }\end{array}$ \\
\hline $\begin{array}{l}\text { Pelosse et al., } \\
\text { (2007) }\end{array}$ & Glucose content & $\mathrm{Val}$ & $1 \mathrm{~b}, \mathrm{c}$ & 24 & $\begin{array}{l}\text { Energy } \\
\text { level }\end{array}$ \\
\hline $\begin{array}{l}\text { Amat et al., } \\
\text { (2012) }\end{array}$ & $\begin{array}{l}\text { Protein content and free carbohydrates } \\
\text { content }\end{array}$ & Val & & 25,26 & $\begin{array}{l}\text { Energy } \\
\text { level }\end{array}$ \\
\hline $\begin{array}{l}\text { Amat et al., } \\
(2012)\end{array}$ & $\begin{array}{l}\text { Glycogen consumption rates during } \\
\text { flight }\end{array}$ & $\mathrm{Val}$ & 2 & 27 & $\begin{array}{l}\text { Energy } \\
\text { level }\end{array}$ \\
\hline $\begin{array}{l}\text { Pelosse et al., } \\
\text { (2007) }\end{array}$ & Lipid content & Val & $1 \mathrm{~b}, \mathrm{c}$ & 28 & $\begin{array}{l}\text { Energy } \\
\text { level }\end{array}$ \\
\hline $\begin{array}{l}\text { Amat et al., } \\
(2012)\end{array}$ & Lipid content & $\mathrm{Val}$ & & 29 & $\begin{array}{l}\text { Energy } \\
\text { level }\end{array}$ \\
\hline $\begin{array}{l}\text { Foray et al., } \\
\text { (2014) }\end{array}$ & $\begin{array}{l}\text { Reaction norm for protein, lipid and } \\
\text { sugar content at different temperatures }\end{array}$ & $\mathrm{Val}$ & 5 & $30,31,32$ & $\begin{array}{c}\text { Temperat } \\
\text { ure }\end{array}$ \\
\hline Amat (2004) & $\begin{array}{l}\text { Proportion of females not recaptured } \\
\text { after release in field conditions }\end{array}$ & Ant & 28 & 33 & Flight \\
\hline $\begin{array}{l}\text { Lukas et al., } \\
\text { (2010) }\end{array}$ & $\begin{array}{l}\text { Number of rest stops per flight of } \\
\text { similar distance }\end{array}$ & Val & 1 & 34 & Flight \\
\hline
\end{tabular}




\begin{tabular}{|c|c|c|c|c|c|}
\hline $\begin{array}{l}\text { Lukas et al., } \\
(2010)\end{array}$ & Speed of the longest flight & Val & & 35 & Flight \\
\hline $\begin{array}{l}\text { Foray et al., } \\
\text { (2011) }\end{array}$ & $\begin{array}{l}\text { Reaction norm for development rate as } \\
\text { a function of temperature }\end{array}$ & Val & $1 \mathrm{~b}$ & 36 & $\begin{array}{c}\text { Temperat } \\
\text { ure }\end{array}$ \\
\hline Amat (2004) & $\begin{array}{l}\text { Time to leave after experimental } \\
\text { release }\end{array}$ & Ant & 27 & 37 & Flight \\
\hline $\begin{array}{l}\text { Amat et al., } \\
\text { (2012) }\end{array}$ & Speed of flight & Val & 3 & 38 & Flight \\
\hline $\begin{array}{l}\text { Lukas et al., } \\
\text { (2010) }\end{array}$ & Speed of flight; & Val & 2 & 39 & Flight \\
\hline $\begin{array}{l}\text { Foray et al } \\
(2013 b)\end{array}$ & Time to recover from chill coma & Val & 1 & 40 & $\begin{array}{c}\text { Temperat } \\
\text { ure }\end{array}$ \\
\hline $\begin{array}{l}\text { Pelosse et al., } \\
\text { (2007) }\end{array}$ & Teneral energy content & Val & $1 \mathrm{a}$ & 41 & $\begin{array}{l}\text { Energy } \\
\text { level }\end{array}$ \\
\hline $\begin{array}{l}\text { Amat et al., } \\
\text { (2006) }\end{array}$ & $\begin{array}{l}\text { Change in the number of ovipositions } \\
\text { in response to change in temperature }\end{array}$ & Ant & 3 & 42 & $\begin{array}{c}\text { Temperat } \\
\text { ure }\end{array}$ \\
\hline $\begin{array}{l}\text { Foray et al., } \\
\text { (2011) }\end{array}$ & $\begin{array}{l}\text { Performance curve for egg load at } \\
\text { emergence as a function of temperature }\end{array}$ & Val & $3 a$ & 43 & $\begin{array}{c}\text { Temperat } \\
\text { ure }\end{array}$ \\
\hline $\begin{array}{l}\text { Barke et al., } \\
(2005)\end{array}$ & Life-time offspring produced & Ant & 7.2 & 44 & Fecundity \\
\hline $\begin{array}{l}\text { Foray et al., } \\
\text { (2014) }\end{array}$ & $\begin{array}{l}\text { Reaction norm for glycogen content at } \\
\text { different temperatures }\end{array}$ & Val & 5 & 45 & $\begin{array}{c}\text { Temperat } \\
\text { ure }\end{array}$ \\
\hline $\begin{array}{l}\text { Pelosse et al., } \\
\text { (2010) }\end{array}$ & Time feeding & Val & & 46 & Feeding \\
\hline
\end{tabular}




\begin{tabular}{llllll}
\hline Barke et al., & Longevity of fed wasps at $29^{\circ} \mathrm{C}$ & Ant & $7.6 \mathrm{~b}$ & 47 & Longevity
\end{tabular}
(2005)

\begin{tabular}{lllll}
\hline Pelosse et al., & Longevity & Val & 48 & Longevity
\end{tabular}

\begin{tabular}{llllll}
\hline Barke et al., & Longevity of fed wasps at $25^{\circ} \mathrm{C}$ & Ant & $7.6 \mathrm{~b}$ & 49 & Longevity
\end{tabular}
(2005)

\begin{tabular}{llllll}
\hline Foray et al., & Longevity & Val & 2 & 50 & Longevity
\end{tabular}

\begin{tabular}{|c|c|c|c|c|c|}
\hline $\begin{array}{l}\text { Pelosse et al., } \\
\text { (2007) }\end{array}$ & Teneral glycogen content & Val & $1 \mathrm{~d}$ & 51 & $\begin{array}{l}\text { Energy } \\
\text { level }\end{array}$ \\
\hline $\begin{array}{l}\text { Pelosse et al., } \\
(2010)\end{array}$ & Teneral glycogen content & Val & $2 \mathrm{c}$ & 52 & $\begin{array}{l}\text { Energy } \\
\text { level }\end{array}$ \\
\hline $\begin{array}{l}\text { Amat et al., } \\
\text { (2012) }\end{array}$ & Glycogen content & Val & 2 & 53 & $\begin{array}{l}\text { Energy } \\
\text { level }\end{array}$ \\
\hline $\begin{array}{l}\text { Foray et al., } \\
\text { (2014) }\end{array}$ & $\begin{array}{l}\text { Performance curve for maximal } \\
\text { fecundity at different temperatures }\end{array}$ & Val & $3 b$ & 54 & $\begin{array}{c}\text { Temperat } \\
\text { ure }\end{array}$ \\
\hline $\begin{array}{l}\text { Foray et al., } \\
\text { (2011) }\end{array}$ & $\begin{array}{l}\text { Performance curve of maximal egg- } \\
\text { load as a function of temperature }\end{array}$ & Val & $3 b$ & 55 & $\begin{array}{c}\text { Temperat } \\
\text { ure }\end{array}$ \\
\hline
\end{tabular}


715 Appendix A: Selected literature for the meta-analysis

We calculated the effect size of reproductive mode for the great majority of the 46

717 traits under study from the 16 papers included in the meta-analysis (see also "overview of

718 the selected literature" section in the main text). Some results, indicated in Appendix A

719 Table 1, were not included in Figure 2 because either a) higher-level interactions impede

720 to interpret the additive effects of reproductive mode and thus to calculate $d$ statistics for

721 these effects (note that when reproductive mode is involved in higher-level interactions but

722 without switch of effect in each reproductive mode, additive effects of mode of

723 reproduction are provided, e.g. point 34 in Figure 2); b) experimental design did not

724 compare the sexual and asexual trait in a single experiment; c) $d$ inappropriate for the

725 statistics used (e.g. non-parametric or semiparametric statistics, multivariate analysis) ; d)

726 the information provided did not allow for statistical comparisons in terms of $d$ values.

\section{Appendix ATable 1}

729

730

731

732 733

734

735
Authors and main results of the comparison between sexual (S) and asexual (A) strains that are not included in Figure 2. Figures in the original paper showing specific results. Comment: reasons that led to their exclusion from Figure 2 (see text for details). PRT: patch residence time. Data from this table were obtained using strains collected at 7 different locations: Antibes (Ant), Valence (Val), Mont Boron (MtB), Valbonne (Valb), Golfe Juan (GJ), Tuscany (Tu) and Algarve (Al). In two cases, some results were considered redundant. In Amat et al. (2006) two similar experiments gave similar results. In Lukas et al. (2010) in the same experiment similar measures 
736 of flight performance yielded similar results. In these two cases a single result was included in

\section{Figure 2.}

\begin{tabular}{|c|c|c|c|c|}
\hline Authors & $\begin{array}{l}\text { Results of comparing sexual versus asexual } V \text {. canescens ; } \\
\text { (origin of the strains) }\end{array}$ & $\begin{array}{l}\text { origin of } \\
\text { the strains }\end{array}$ & $\begin{array}{l}\text { Figures in } \\
\text { original } \\
\text { paper }\end{array}$ & Comment \\
\hline Amat (2004) & $\begin{array}{l}\text { Recapture rate in the field: } 11 \% \text { of all captures in field } \\
\text { transects are A and } 89 \% \mathrm{~S} \text {. In } 19.5 \% \text { of the samplings A and } \\
\text { S coincided in recapture date and location }\end{array}$ & Val & 22,24 & $d$ inappropriate \\
\hline \multirow{2}{*}{$\begin{array}{l}\text { Barke et al., } \\
(2005)\end{array}$} & Higher longevity for fed $\mathrm{S}$ at $15^{\circ} \mathrm{C}$ & Ant & 7.6 & $d$ inappropriate \\
\hline & $\begin{array}{l}\text { No significant differences in longevity for unfed } \mathrm{A} \text { and } \mathrm{S} \text { at } \\
15,25 \text { and } 29^{\circ} \mathrm{C}\end{array}$ & Ant & 7.6 & $d$ inappropriate \\
\hline $\begin{array}{l}\text { Liu et al., } \\
(2009 a)\end{array}$ & $\begin{array}{l}\text { PRT depends on "travel time" : S use flying time between two } \\
\text { successive patch encounters while A simply use waiting time } \\
\text { (either flying or resting) }\end{array}$ & Ant, Val & 4 & Experimental design \\
\hline $\begin{array}{l}\text { Lucchetta et } \\
\text { al., (2007) }\end{array}$ & $\begin{array}{l}\text { The effect of the number of ovipositions on PRT is differently } \\
\text { affected by the mode of reproduction (A or S), depending on } \\
\text { the origin of the animals (Ant or Val). For the wasps from } \\
\text { Antibes, each oviposition decreases stronger the PRT in A than } \\
\text { in S. In Valence, the effect of the number of ovipositions is } \\
\text { independent of the reproductive mode }\end{array}$ & Ant, Val & 4 & $\begin{array}{l}\text { Higher level } \\
\text { interaction }\end{array}$ \\
\hline $\begin{array}{l}\text { Lucchetta et } \\
\text { al., (2008) }\end{array}$ & $\begin{array}{l}\text { No difference between } \mathrm{A} \text { and } \mathrm{S} \text { in their ability to learn a color } \\
\text { associated with a food reward }\end{array}$ & Val & 3 & $d$ inappropriate \\
\hline $\begin{array}{l}\text { Foray et al., } \\
(2014)\end{array}$ & $\begin{array}{l}\text { The shape of the reaction norm for developmental rate differs } \\
\text { with the reproductive mode: } \mathrm{S} \text { females reach higher maximal } \\
\text { growth rate than the A females do. The shape is also affected } \\
\text { by the thermal regime, with a decrease of the developmental } \\
\text { growth rate at } 25 \text { and } 30^{\circ} \mathrm{C} \text { under the fluctuating regime }\end{array}$ & Val & $2 b$ & $\begin{array}{l}\text { Higher level } \\
\text { interaction }\end{array}$ \\
\hline $\begin{array}{l}\text { Foray et al., } \\
\text { (2013a) }\end{array}$ & $\begin{array}{l}\text { Metabolite profile differences in response to thermal change: } \\
\text { phenylalanine, threonine and serine were more abundant in the } \\
\text { S, while maltose, succinate, sucrose and glycerol were more } \\
\text { abundant in the A }\end{array}$ & Val & 2 & $d$ inappropriate \\
\hline
\end{tabular}




\begin{tabular}{|c|c|c|c|c|}
\hline $\begin{array}{l}\text { Pelosse et al., } \\
\text { (2007) }\end{array}$ & $\begin{array}{l}\text { The relationship between egg load at death and longevity: } \\
\text { resource availability during ontogeny and reproductive mode } \\
\text { affect this relationship. When resource are highly available, S } \\
\text { live longer than A and have fewer eggs than their A } \\
\text { counterparts. When the A and S wasps develop in low resource } \\
\text { available conditions, they decrease both in fecundity and } \\
\text { longevity }\end{array}$ & Val & 2 & $\begin{array}{l}\text { Higher level } \\
\text { interaction }\end{array}$ \\
\hline $\begin{array}{l}\text { Pelosse et } \\
\text { al., (2010) }\end{array}$ & $\begin{array}{l}\text { Fructose amounts during lifetime is affected by size in } \\
\text { interaction with reproductive mode }\end{array}$ & Val & $2 a, b$ & $\begin{array}{l}\text { Higher level } \\
\text { interaction }\end{array}$ \\
\hline \multirow{3}{*}{$\begin{array}{l}\text { Thiel et al., } \\
\text { (2006) }\end{array}$} & No differences in giving up time between $\mathrm{S}$ and $\mathrm{A}$ & Ant, Val & 3 & $\begin{array}{l}\text { Insufficient } \\
\text { information and higher } \\
\text { level interaction }\end{array}$ \\
\hline & $\begin{array}{l}\text { A reduce their PRT with successive visits to patches in a rich } \\
\text { environment (in terms of host patches); in contrast, } \mathrm{S} \text { females } \\
\text { do not modify their behavior with experience }\end{array}$ & Ant, Val & 4 & $\begin{array}{l}\text { Insufficient } \\
\text { information and higher } \\
\text { level interaction }\end{array}$ \\
\hline & $\begin{array}{l}\text { Higher oviposition rate with successive visits to host patches } \\
\text { in A than in S }\end{array}$ & $\begin{array}{l}\text { Ant, Val, } \\
\text { Valb, GJ, } \\
\text { Tu, Al }\end{array}$ & 8 & $\begin{array}{l}\text { Insufficient } \\
\text { information }\end{array}$ \\
\hline $\begin{array}{l}\text { Thiel et al., } \\
\text { (2013) }\end{array}$ & $\begin{array}{l}\mathrm{S} \text { are not more effective learners than A females in a context } \\
\text { of associative learning of stimuli related to hosts }\end{array}$ & $\begin{array}{l}\text { Ant, Val, } \\
\text { MtB }\end{array}$ & 3 & $\begin{array}{l}d \text { inappropriate } \\
\text { Low sample size }\end{array}$ \\
\hline
\end{tabular}

740 When reared on its host Ephestia kuehniella, asexual V. canescens tend to be larger than their

741 sexual counterparts (differences in hind tibia length indicated by points 10-15 in Figure 2. See

742 points 14 and 15, for non-significant differences). In most of the original analysis performed in

743 papers listed in table 1, trait measurements are corrected for size by taking the size as the first

744 covariate in statistical models. This allows revealing the differential investment effort in traits for

745 individuals of the two modes of reproduction. 
747 differences between sexual and asexual $V$. canescens, we standardized the mean differences

748 between strains in terms of the standard deviations of the difference. This yields effect size

749 measurements (Cohen's $d$ value, Cohen, 1988) devoid of units and thus comparable in a meta-

750 analysis approach. $d$ is defined as

751

$$
d=\frac{m_{1}-m_{2}}{S_{\text {pooled }}}
$$

752 with

$$
S_{\text {pooled }}=\sqrt{\frac{\left(n_{2}-1\right) s_{2}^{2}+\left(n_{1}-1\right) s_{1}^{2}}{n_{1}+n_{2}-2}}
$$

754 where $m_{1}$ and $m_{2}$ are the mean values for two groups, $s_{1}^{2}$ and $s_{2}^{2}$ are the variances and $n_{1}$ and $n_{2}$ 755 are the sample sizes.

756 The parameter $d$ might be calculated using different expressions. We used the expression suggested

757 by Nakagawa and Cuthill (2007)

$$
d=\frac{t\left(n_{1}+n_{2}\right)}{\sqrt{n_{1} n_{2} d f}}
$$

760 where $t$ is Student's statistic obtained from the statistical analysis and $d f$ is the number of degrees

761 of freedom used for a corresponding $t$ value.

762 The approximated $95 \%$ confidence intervals $(95 \% \mathrm{CI})$ of $d$ are given by 
764 where $s e_{d}$ stands for the asymptotic standard error. There are several mathematical expressions 765 that allow for the calculation of this value. Here we used (Hunter and Schmidt 2004)

$$
s e_{d}=\sqrt{\left(\frac{n_{1}+n_{2}-1}{n_{1}+n_{2}-3}\right)\left[\left(\frac{4}{n_{1}+n_{2}}\right)\left(1+\frac{d^{2}}{8}\right)\right]}
$$

767 This expression is adequate for Cohen's $d$, although it might provide biased estimates for small 768 sample sizes. We calculated both biased and unbiased estimates. The differences between biased 769 and unbiased estimates proved to be negligible (results not presented). The results of the analysis 770 of continuous response variables performed by means of generalized linear models express the 771 significance of a given process in terms of $F$ values. As two groups were compared, the number of 772 degrees of freedom for the treatments is 1 , and $t$ can be calculated as suggested by Nakagawa and 773 Cuthill (2007):

$$
t_{n \mathrm{df}}=\sqrt{F_{1, n \mathrm{df}}}
$$

775

776

777 778

779

780

781 782

When statistical models expressed significance in terms of the normal distribution, in the relevant equations we used the $z$ values to replace the $t$ values, calculating the degrees of freedom as if $t$ tests were used (Nakagawa \& Cuthill 2007).

In these calculations, positive $d$ values stand for the case where a trait value is higher in sexuals. In some cases, the trait measured is negatively correlated with the investment in the category under study. These cases are: number of stops during a flight covering a given distance (negatively correlated to flight investment because this implies shorter flight bouts, point 34 in Figure 2); time 
783 to leave release apparatus in the wild (negatively correlated to flight investment, point 37 in Figure

784 2) and time to recover from chill coma (negatively correlated to ability to deal with changing

785 temperature, point 40 in Figure 2). In these cases, we changed the sign of the $d$ value. In this way,

786 in Figure 2 all positive $d$ values correspond to cases where sexuals invest more than asexuals in a

787 given category (size, fecundity, longevity, energy level, flight, superparasitism, feeding and

788 temperature). When dealing with reaction norms or performance curves (points 17-18, 21-22, 30-

789 32, 36, 43, 45 and 54-55 in Figure 2), we approximated the relationship between the measured trait

790 and temperature for each form by a parabola. The coefficient for the interaction between mode of

791 reproduction and temperature squared is compared to 0 in order to test the differences in shape

792 between the two curves. Calculations were performed such that positive $d$ values would correspond

793 to steeper concave curves for asexuals. This corresponds to situations in which i) sexual parasitoids

794 present shallower and broader curves, allowing high reproduction rates for a wider range of

795 temperatures, and ii) asexual wasps, having narrower response curves, maximize reproductive

796 success under a restricted thermal range. 